la006@umn.edu]. Her research interests include two-year tech-

nical and community colleges, teacher retention, evaluation and assessment, and Tech Prep education programs.

\section{Judgment of Factors Influencing Interest: An Australian Study}

\section{James A. Athanasou}

University of Technology, Sydney, Australia

\section{Ray W. Cooksey}

University of New England, Australia

\begin{abstract}
The purpose of this study was to investigate factors that influence interest in vocational education subjects. The 20 factors that were investigated related to the course, ability, difficulty, relevance or importance of a subject, the quality of teaching, student effort, career and vocational interests, as well as demographic factors. The source data used in the study comprised 120 previously obtained student scenarios. Participants $(N=18)$ from technical and further education acted as judges. They read the information in each of the scenarios and were asked to judge how interested they would be in taking the vocational education subject described. The multiple correlation of the 20 items in each scenario with ranked interest was 0.84 yet the median correlation of judgments was only 0.305. Overall, career interests were rated more importantly than other factors. Results confirmed the idiosyncrasy of interest perceptions and it was concluded that individual differences have an impact on the ways in which people determine their interest for learning.
\end{abstract}

This paper focuses on the area of educational interest and the specific purpose of this study is to determine which factors might influence a person's interest in a vocational education subject. Interest is a meaningful field for practical as well as 
theoretical research and as far back as 1913, it was emphasised by Dewey as important for learning. Earlier work has related interest to topic recall (Renninger, 1992) as well as educational achievement (Schiefele, Krapp \& Winteler, 1992; Athanasou, 1994) but has not focused upon factors influencing interest.

\section{Components of Interest}

Any applied investigation of interests might build usefully upon a range of modern German theories that have direct relevance for vocational learning (Athanasou, 1998a). These approaches view interest as a construct that characterises a person's special relationship with content, topics, subjects or a domain. A distinction is made between (a) individual interests that are content specific and an enduring characteristic of a person's behaviour, and (b) those situational factors that promote attention, arousal or the development of specific interest. Figure 1 provides a tentative model that incorporates those factors relevant to this study.

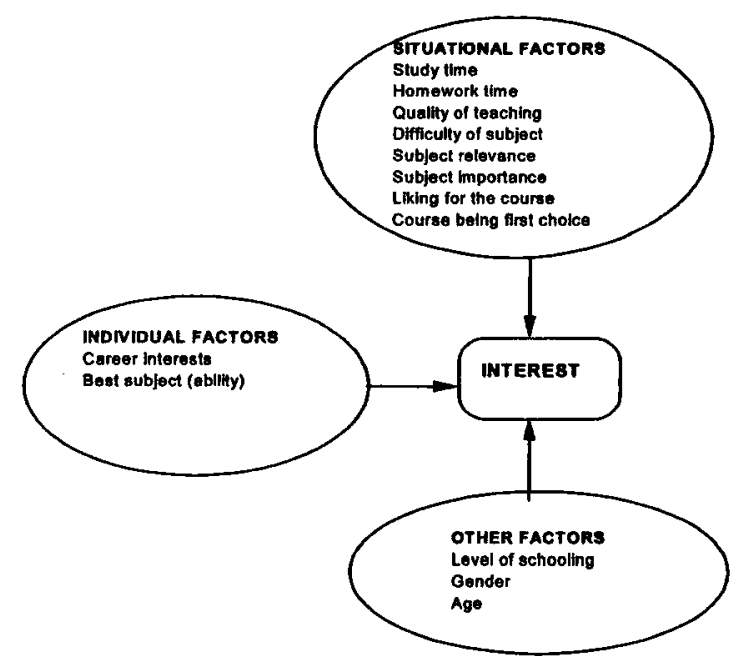

Figure 1. A tentative model of individual, situational, and other factors affecting subject interest.
Some of these individual and situational interest factors were investigated in a study of 940 technical and further education students from some 20 colleges and 60 courses (Athanasou, 1998b). They included, amongst others, the importance of the subject, the relevance of the course to students, whether it was their best subject, their easiest subject, the quality of teaching, the amount of time spent on homework and time spent studying. In addition to these factors, social and demographic variables together with vocational interests ands course preferences were also investigated. Results indicated that there were no effects of gender, age, mode of study (part time or full time) on the extent of subject interests. Rankings of interest were, however, related more to factors such as the best and easiest subjects, the most relevant and most important subjects and to a lesser extent, quality of teaching, study and homework time.

The present study is an extension of this research and now considers how individuals might determine their interest in a subject. It investigates which factors a person considers important when he/she decides how interested they are in a subject. It was hypothesised that on the basis of the earlier findings, people will probably give greater emphasis to factors such as importance, relevance or being best at a subject.

The practical importance of the study arises from the fact that if we know which factors affect a person's interest then it may enable us to manage classroom learning, and to maximise student motivation or to better advise students about their course and career options. While previous research (Athanasou, $1994 ; 1998 \mathrm{~b}$ ) focused on large-scale surveys, it is not clear to what extent these findings can be applied to individual students. This study focuses on the intensive study of an individual and represents the application of judgment analysis to the topic of interest. In 1968, Snow advocated an approach to research on teaching that called for analyses of individual rather than group classroom behaviours (Snow, 1968). This emphasised multiple 
sampling within an individual as opposed to sampling of multiple individuals. It represents a powerful design and contrasts sharply with group studies, which are popular in modern research but which cannot describe the behaviour of a single person or produce results that are transferable to new situations. The following section outlines some aspects of judgment analysis and the design of the study.

\section{Judgment Analysis}

Within these single person approaches, judgment analysis provides an ideal experimental basis for the investigation of decision making in a real situation (Cooksey, 1996). It permits a description of which factors are affecting a judgment and also enables a comparison between the judgments of an individual and a criterion. Judgment analysis breaks down human deci-

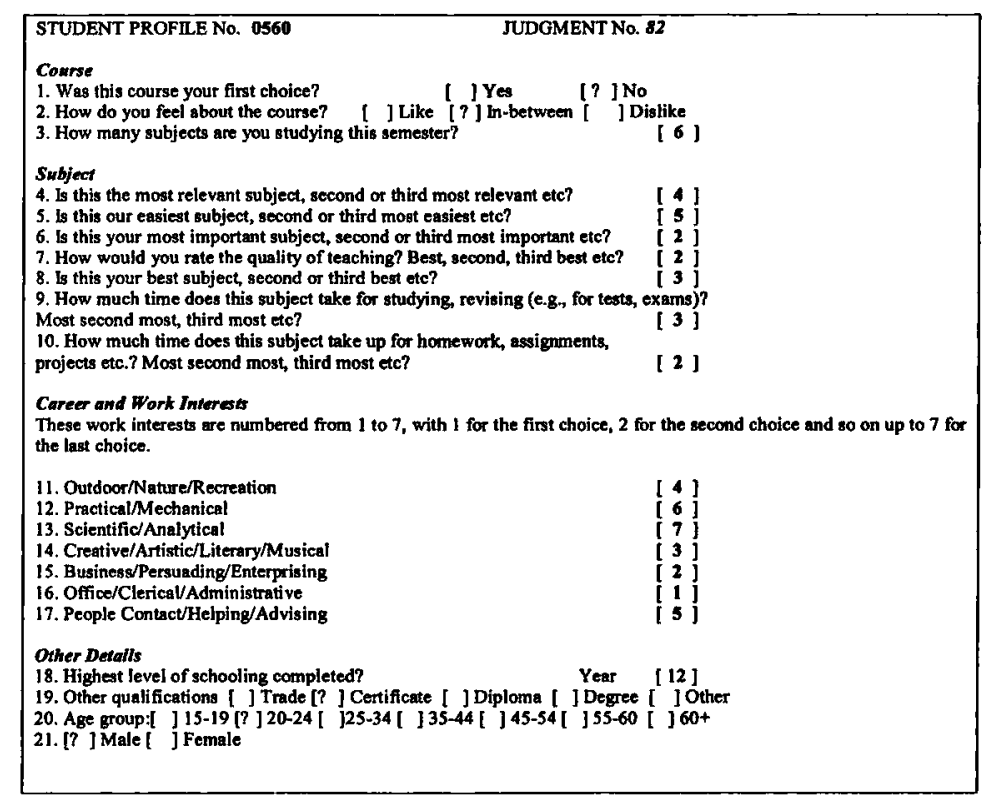

Figure 2. A sample scenario of information about an actual student and the technical and further education subject they were studying. sions into their components and some aspects of this approach are described in the following paragraphs.

Assume for a moment that we present repeated scenarios of information about a student and their response to a subject that they are studying to a judge (a sample scenario of information is depicted in Figure 2). Given the background information contained in the scenario, the judge is asked how interested he or she would be in studying a particular subject. Since each scenario contains the same set of items or cues for judgment, it is then possible to analyse which items are important to the judge and we can even decompose their judgment into several components. If the scenarios we used for the judgment analysis are taken from real students then the design of the study is representative. We are able to make generalisations to other situations or scenarios for this particular judge, but of course we would not make generalisations to other people. This whole approach was derived from the analysis of perceptions (Brunswik, 1956).

The astute reader might ask why we do not ask people which factors are most important to them in deciding whether they are interested in a subject. This was done already in the study referred to earlier (Athanasou, 1998b) and it was noted that the most important factors were subject specific factors, such as ability, difficulty, relevance, importance quality of teaching etc. The results of this earlier study, however, did not tell us which factors were consistently important to a particular person across many different subjects. Judgment analysis describes someone's decision making across a range of representative situations by asking them to place themselves in each scenario and to make a judgment about how interested he or she might be in taking a particular subject. The situation is certainly contrived but at the same time it is reasonably representative and there are precedents for this approach (see Athanasou, 1998c; 1999).

Furthermore, if we knew at the outset how much the person 
depicted in the scenario was interested in their subject, then we would also be able to make comparisons between the judge's judgments across many scenarios and the interest in each of those scenarios. It is then possible to formulate an identity:

$$
r_{a}=G R_{e} R_{s}+C \sqrt{ }\left(1-R_{e}\right)^{2} \sqrt{ }\left(1-R_{s}\right)^{2}
$$

where:

$r_{a}=\quad$ the achievement index (i.e., the correlation between a judge's estimate and the ranked levels of interest for all scenarios)

$R_{e}=$ the predictability index (i.e., the multiple correlation of the items with the ranked level of interest for all scenarios)

$R_{s}=\quad$ cognitive control (i.e., the multiple correlation of the items with the judge's estimate for all scenarios)

$\mathrm{G}=$ a knowledge index (i.e., the correlation between the predicted levels of interest and the predicted judgments for all scenarios)

$\mathrm{C}=\quad$ an unmodeled knowledge (i.e., the correlation between the residuals from the above predictions).

Hursch, Hammond and Hursch (1964) developed this identity (subsequently simplified by Tucker, 1964) in which it is assumed that achievement (i.e., judgment performance) is equal to knowledge times task predictability times cognitive control plus an unmodeled component.

In this study we obtained 120 scenarios from a group of vocational education students. These scenarios contained 20 cues or items of information about each student and his or her ranking of some features of the subject described in the tentative model of interest (see Figure 1). The cues or items of information were derived from the earlier study on interest (Athanasou, 1998b). They can be categorised broadly and tentatively as (a) those which are pertinent to individual interest and which are evaluative as well as relatively enduring in nature (see Schiefele \& Krapp, 1996); (b) those which are pertinent to the situation, such as subject importance or subject relevance, quality of teaching etc. (see Hidi, 1990); and, (c) those factors which are demographic, such as level of schooling, age or gender, and which in previous studies have been seen to circumscribe interest to some extent (see Gottfredson, 1996).

For each student and scenario, however, there was also a criterion measure or outcome. In this study, the criterion was unknown to the judge but was known to the researchers. The criterion was the subject's interest ranking by the person described in each scenario. (The ranking was converted to a common measure (see Athanasou, 1994). For instance, if a person was studying four subjects in their course last semester then they were asked to rank the specific subject in terms of how interesting it was for them out of all the four subjects that they studied.) These multiple scenarios are presented to a separate group acting as judges and from this it is possible to describe the features of each person's judgments that are summarised in the judgment analysis equation.

This description is done statistically because each judge makes repeated judgments that can be analysed as a quantitative case study. In effect, it is an intensive study of a person across repeated situations. The equation indicates the components or decomposition of the judgment. We use multiple regression techniques to determine which cues or items were relied upon to make judgments and achievement $\left(r_{a}\right)$ indicates the correlation between each person's judgments and the criteria (i. e., the subject interest rankings). A powerful feature of the equation is that it forms an identity in which one's perception of reality can be equated with a subset of its components ( $G$, $\left.R_{e}, R_{s}, C\right)$ that are described above. It is recognised that this model and approach may be unfamiliar to many readers.

It allows one to consider judgments from two perspectives. Firstly, we can consider how judges made use of the different 
cues or items of information in each scenario (these are the correlations between each cue and the repeated judgments). Secondly from the judge's perspective we can consider his/her overall use of the cues and make some predictions using multiple regression about what might have been his/her judgment. We can determine the residual between the actual judgment and a predicted judgment. This is called their cognitive control over the judgment process $\left(\mathbf{R}_{\mathbf{s}}\right)$.

In addition to analysing the person's judgments or perceptions we also have detailed knowledge about the scenario. From the outset we had 120 scenarios containing items of information and the interest rankings of the persons described in the scenarios. This means that we knew the correlation between each item of information and interest in the subject. The multiple regression between the cues and these 120 criteria can be studied to determine which factors are really important from the outset. Knowledge (G) reflects the understanding of the task requirements (i.e., the correlation between predicted judgments and predicted criterion). Task control $\left(R_{e}\right)$ is the correlation between the actual criterion and estimated criterion scores and reflects the upper limit of a person's potential judgment achievement (i. e., predictability)

\section{Research Questions}

Using judgment analysis it is possible to describe how a person might go about deciding that they are interested in learning. This paper reports a detailed analysis of how 18 judges reacted to situations and each of these judges is a separate study of the factors that might potentially influence interest in vocational education. From both a theoretical and practical perspective it is important for us to know what factors are linked with interest. In this study the research questions were: (a) how does a person estimate his/her interests; and (b) which factors does he/she take into account when determining interest in technical and further education?

\section{Participants}

\section{Method}

The judges for this study comprised 20 technical and further education students ( 7 males; 13 females) who ranged in age from 15 to 60 years and comprised 17 full time and three part time students. Most $(N=16)$ had completed the highest level of secondary schooling and 10 had previous educational qualifications ( 3 certificate; 2 diploma; 5 degree). Results from two judges were discarded because they had difficulty with the task and consistently made judgments out of the permissible range.

\section{Procedure}

The study was conducted through the Sydney Institute of Technology. Permission to conduct the research was obtained from the Director of the Institute who arranged for an outline of the study to be provided to potential participants. Participants were advised that involvement was voluntary and confidential and that no names would be recorded. To encourage a high quality of data collection and accuracy, judges were offered two movie tickets for participating. Participants made appointments and the study was conducted off-site and with groups of varying size at the adjacent University of Technology, Sydney. No claim is made for the representativeness of the sample.

\section{Instrument}

Judges were handed a pre-printed book containing 120 scenarios of students who had completed surveys as part of the study by Athanasou (1998). Identifying details were deleted from the surveys. The surveys $(N=120)$ were randomly selected from the 940 in that earlier survey.

Judges made 120 judgments of the level of interest after looking at each profile of information. They were asked to rank how interested they would be in this subject out of the total number of subjects studied. This provided a ranked estimate of interest. Judgments were then compared with the ranking of in- 
Table 1

Correlations and Standardised Estimates Between Interest and 20 Independent Variables (Cues) in the Ecology $(N=120)$

\begin{tabular}{|c|c|c|}
\hline Cue & $\begin{array}{l}\text { Correlation with } \\
\text { interest } \\
\text { (cue validities) }\end{array}$ & $\begin{array}{l}\text { Standardised } \\
\text { estimates }\end{array}$ \\
\hline Whether course was first choice & .146 & -.075 \\
\hline Whether the student liked the course & $.217^{*}$ & .059 \\
\hline Relevance of the subject & $.459 * *$ & -.045 \\
\hline Whether it was their easiest subject & $.558 * *$ & $.286^{\mathrm{a}}$ \\
\hline $\begin{array}{l}\text { Whether it was their most important } \\
\text { subject }\end{array}$ & $.321 * *$ & $.199^{\mathrm{a}}$ \\
\hline Quality of teaching & $.243 * *$ & $-.177^{\mathrm{a}}$ \\
\hline Whether it was their best subject & $.719 * *$ & $.613^{\mathrm{a}}$ \\
\hline $\begin{array}{l}\text { Amount of study time relative to } \\
\text { other subjects }\end{array}$ & -.004 & .157 \\
\hline $\begin{array}{l}\text { Amount of homework time relative } \\
\text { to other subjects }\end{array}$ & -.099 & $-.225^{\mathrm{a}}$ \\
\hline Career interest: Outdoor & -.042 & .136 \\
\hline Career interest: Practical & .132 & .251 \\
\hline Career interest: Scientific & -.064 & .011 \\
\hline Career interest: Creative & $-.372 * *$ & -.066 \\
\hline Career interest: Business & $.185^{*}$ & .110 \\
\hline Career interest: Office & $.184^{*}$ & .041 \\
\hline Career interest: People Contact & -.089 & .145 \\
\hline School Level & .164 & .042 \\
\hline Other qualifications & -.075 & -.057 \\
\hline Age & -.145 & -.022 \\
\hline Gender & .161 & .001 \\
\hline
\end{tabular}

${ }^{*} p<.05 ;{ }^{* *} p<.01 ;{ }^{\mathrm{a}} t$-value $(\mathrm{b}=0) p<.01$

terest stated by the original student in each scenario.

\section{Judgment Analysis}

Prior to analyses of individual judgments, the validity of each of the 20 cues for the 120 profiles was determined. The multiple correlation of the 20 cues with actual interest was 0.84 indicating a relatively high degree of task structure in the prediction of interest. The correlation coefficients between each cue and the ecological criterion, subject interest, are indicated in Table 1 together with the standardised estimates (beta weights). Looking at the standardised estimates (Table 1), the easiest subject, quality of teaching, best subject, homework time and the importance of the course were amongst the most important predictors of interest. The regression coefficients were considered because they indicated the standardised amount by which interest would vary if an item increased by one standardised unit while simultaneously holding all other values constant. (The pre-printed book of 120 profiles, the matrix of cue correlations, the cue validities for each person, and the relative beta weights are available from the authors upon request.)

\section{Reliability}

To check that judges were making consistent decisions, 20 out of the 100 scenarios were randomly selected then added as repeat tasks. Test-retest correlations of these scenarios (see the last numerical column in Table 2) with the original 20 were computed in order to determine if each judge was consistent in his/her decisions. Consistency in judgments varied markedly from 0.023 to a maximum of 1.0 in this group (median = $0.669)$.

\section{Analysis}

The analysis of the judgments was undertaken for each individual using the judgment analysis equation as the framework. The multiple regression of the 20 cues on judgments of interest was calculated together with the additional indices, cognitive control, knowledge and task control. The results are reported in several stages. Firstly, the judges' responses are considered individually then overall judgment policies are described. Full details of the analysis are provided in the results 
section.

\section{Results}

At the outset, it should be noted that the judges in this study were operating in a reasonably predictable environment $\left(\mathrm{R}_{e}=\right.$ 0.84 ) but one in which none of the 20 items by itself would permit optimal prediction. A complex combination of cues (especially best subject, easiest subject, homework time, importance, quality of teaching,) was required to maximise achievement $\left(r_{a}\right)$. Each judge's performance, however, really needs to be described on its own and the individual judgment analysis indices are reported in Table 2.

\section{How did People Estimate their Interests?}

Taking Judge $A$ as an example for individual interpretation, it can be seen that this person's level of achievement in the judgment task was low $\left(r_{a}=0.32\right)$ but that the level of cognitive control over his/her judgments was extremely high $\left(\mathrm{R}_{\mathrm{s}}=\right.$ $0.997)$. The judge was only moderately aware of the requirements of the task $(\mathrm{G}=0.379)$ and the unmodeled component of his/her knowledge was close to zero $(C=0.059)$. He/she was remarkably consistent or stable in the pattern of judgments (test-retest reliability $=0.995$ ). Similar individual explorations can be made for each judge to describe their response.

For instance, Judge $C$ had the lowest level of achievement in judgments $\left(r_{a}=0.005\right)$ and the level of cognitive control $\left(R_{s}\right.$ $=0.533$ ) over his/her judgments was much lower than Judge A. This judge had minimal knowledge of the requirements of the task $(\mathrm{G}=0.016)$ and the unmodeled component of his/her knowledge was also close to zero $(\mathrm{C}=-0.004)$. Nonetheless he/ She was quite stable in the pattern of judgments (test-retest reliability $=0.974$ ). Table 2 provides only a quantitative summary of the judgment analysis and the remaining judges can be characterised in a similar fashion.

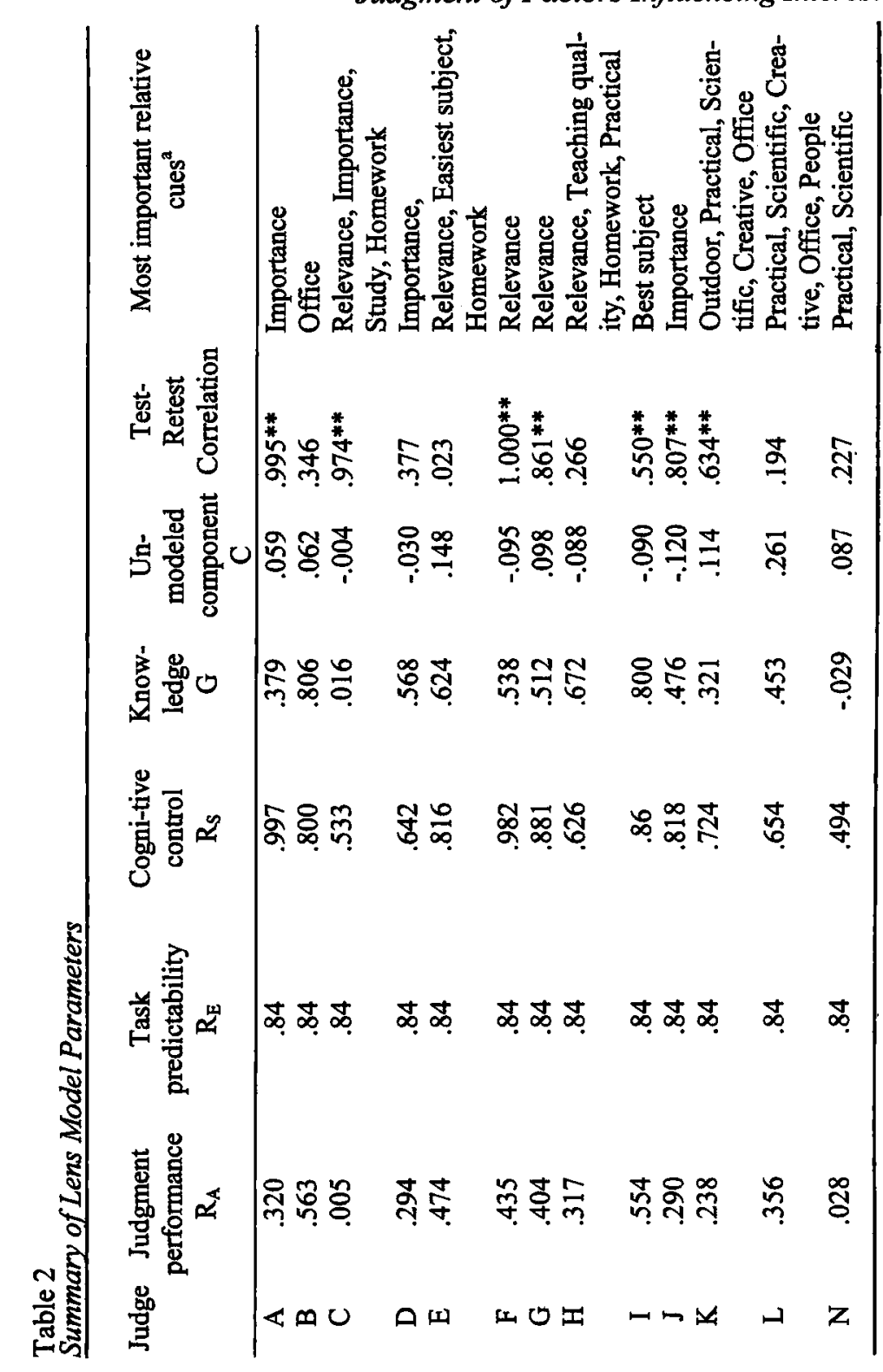




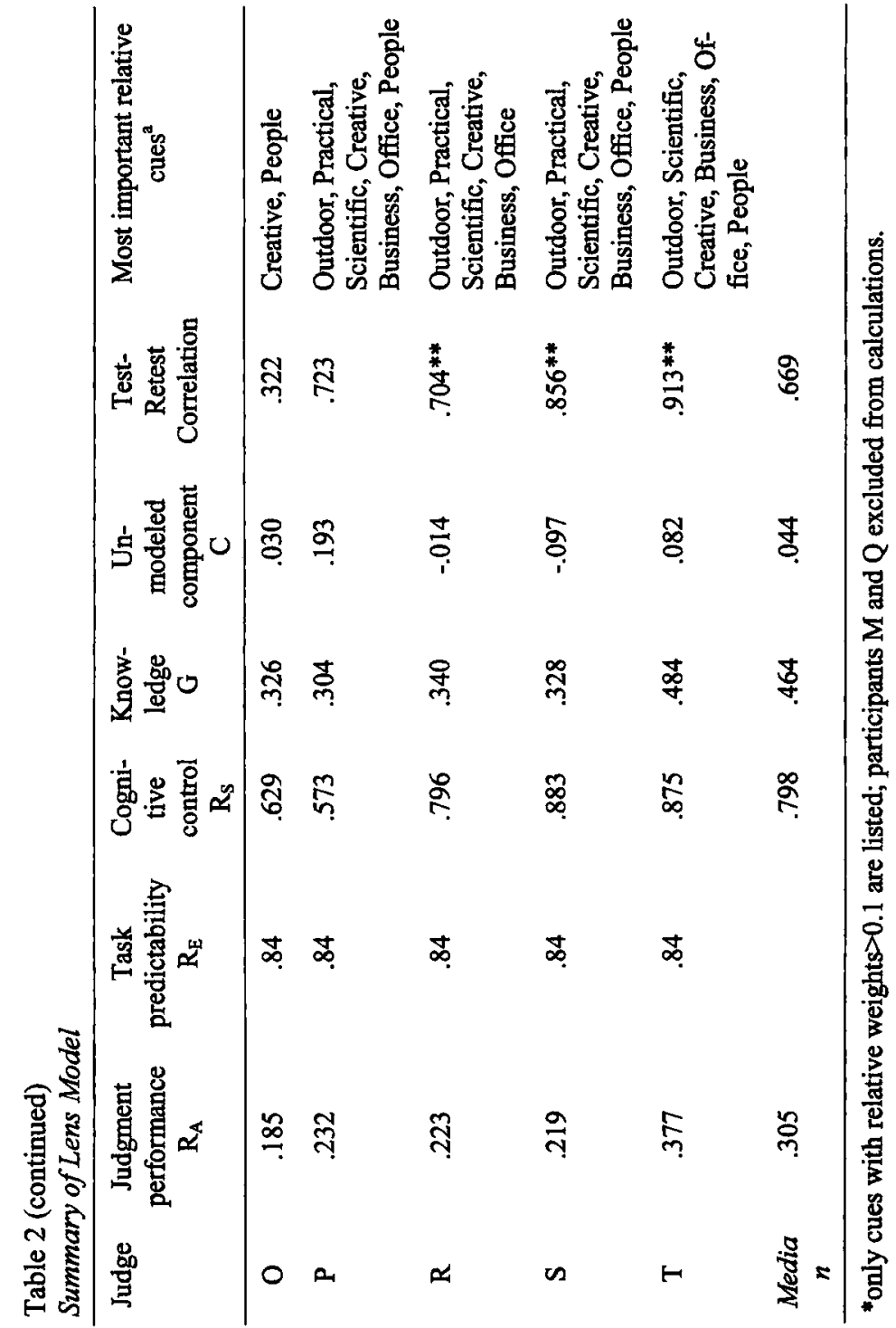

\section{Overall Responses}

The correlations $\left(r_{\mathrm{a}}\right)$ of judgments with interest varied from 0.005 to 0.563 (median=.305) and there was marked variability in their capacity to judge the level of interest (see Table 2 for the individual indices and the first column for the values of $r_{\mathrm{a}}$ ). A combination of cues was used to make judgments as indicated in the multiple correlations $\left(R_{\mathbf{S}}\right)$ in Table 2, of around 0.798 (range 0.494 to 0.997 ). This multiple correlation between cues and judgments was high, but the degree of knowledge of the environment varied from one judge who had negative knowledge of the environment $(-0.029)$ to other judges who had high levels of knowledge (0.806).

Which Factors did People Take into Account when Determining their Level of Interest in Technical and Further Education?

Judges differed in the extent to which they placed their emphasis on different cues. This is seen in the relative beta weights, which represent the proportion of the total of the absolute values of the beta weights. Relative beta weights permit a simple proportional explanation for cue emphasis, for example, a relative weight for a cue of 0.2 would suggest that a judge placed $20 \%$ of all cue weight on that cue (see Cooksey, 1996, pp.168-170 for a discussion of relative beta weights). To assist the reader, medians of the relative beta weights are reported in the final column of Table 3 and these indicated that judges placed relatively greater emphasis for themselves on vocational content (i.e., the career interest area) followed by whether a subject was their best subject, the importance of the subject and its relevance.

\section{Discussion and Conclusions}

This study considered the separate interest judgments of vocational education using a representative experimental design. The findings indicated that personal judgments of vocational educational interest are based firstly on individual factors 
Table 3

Median Relative Beta Weights of the 20 Items of Information in Each Scenario

\begin{tabular}{|c|c|}
\hline Cue & $\begin{array}{l}\text { Median Relative Beta } \\
\text { Weights of Cues }\end{array}$ \\
\hline Whether course was first choice & 0.024 \\
\hline Whether the student liked the course & 0.027 \\
\hline Relevance of the subject & 0.029 \\
\hline Whether it was their easiest subject & 0.017 \\
\hline Whether it was their most important subject & 0.030 \\
\hline Quality of teaching & 0.016 \\
\hline Whether it was their best subject & 0.033 \\
\hline $\begin{array}{l}\text { Amount of study time relative to other sub- } \\
\text { jects }\end{array}$ & 0.013 \\
\hline $\begin{array}{l}\text { Amount of homework time relative to other } \\
\text { subjects }\end{array}$ & 0.027 \\
\hline Career interest: Outdoor & 0.060 \\
\hline Career interest: Practical & 0.083 \\
\hline Career interest: Scientific & 0.069 \\
\hline Career interest: Creative & 0.051 \\
\hline Career interest: Business & 0.032 \\
\hline Career interest: Office & 0.081 \\
\hline Career interest: People Contact & 0.070 \\
\hline School Level & 0.010 \\
\hline Other qualifications & 0.012 \\
\hline Age & 0.012 \\
\hline Gender & 0.015 \\
\hline
\end{tabular}

such as career interests rather than on contextual/situational or extraneous factors. The most popularly used cues by judges were by far the career interests, followed by ability then factors such as importance and relevance.

Of course, the emphasis on career interests may be a feature of technical and further education in Australia, which is largely adult and vocational in orientation from trade to graduate level. The results may need to be replicated for other educational contexts. For instance, it is difficult to imagine how career bases for judgments of interest could be applied to the developing interests of children in elementary schools. Another feature of the judgments was that they did not reflect classroom factors; for example, quality of teaching was not considered most important for the level of interest. This may be intriguing for some readers but it is consistent with two separate and earlier studies of Athanasou $(1994,1998 \mathrm{~b})$ in technical and further education. It may reflect the situation, that for the most part vocational education teaching is of reasonably uniform quality and usually rated highly by students (see Athanasou \& Petoumenos, 1998).

Analysis of the relative cue weights indicated a plethora of judgment policy combinations and confirmed idiosyncrasies in perceptions relating to the judgment of interest in vocational education subjects (cf. Athanasou, 1998b). It was difficult to discern any unequivocal or unique strategy that represented the judgment policy used to decide interest. The best that can be said is that students largely ignored the following factors: whether the course was the person's first choice; whether they liked the course; teaching quality; study time and homework times; level of schooling; other qualifications; age and gender. Such individual variations in judgment ability may have an impact for teachers in their reactions to students.

Results confirmed the emphasis that needs to be given to some factors when career interests are held constant. In particular, factors such as relevance, importance and ability may prove to be useful predictors once we know that a person's career in- 
terest has been satisfied.

In essence, the judges represented 18 separate studies in which the findings did not support a uniform pattern of decision making when it came time to decide about one's vocational education interests. The actual sample in this study is not the 18 judges but the 120 scenarios that represented vocational education situations. Accordingly, one limitation of this study is the extent to which these 120 scenarios are truly representative of vocational education subjects. A further limitation is the extent to which judges were able to cope with a decision-making task involving 20 cues or items of information. Finally there is the important issue of the extent to which the logical inference from a judge's perception based on the 120 people in the scenarios is valid and could rightly be generalised to other contexts.

This analysis of motivation in classroom contexts allowed one to distinguish between what is actually happening in situations, what participants perceived to be happening and what researchers may theorise has happened. The a priori classification of interests into individual, contextual/situational and extraneous components was clear-cut in these individuals because it was the longstanding dispositions (e.g., career interests, ability) that dominated a person's perceptions. The results of this study suggest that it will not be easy for vocational education teachers to manage or influence the perception of interest in a classroom. To a large extent, the interest of a student may be influenced well before he/she even enters a class. Certainly there is scope for further exploration of the links between individual interests and ability and it is also hoped that Snow's (1968) suggestions for individual analyses of behaviour may find ready application in further studies using judgment analysis.

\section{Acknowledgment}

The helpful comments of three anonymous reviewers and the assistance of Kylie Heffernan in the conduct of the study is gratefully acknowledged.

\section{References}

Athanasou, J. A. (1994). Some effects of career interests, subject preferences and quality of teaching on the educational achievement of Australian technical and further education students. Journal of Vocational Education Research, 19, 23-38.

Athanasou, J. A. (1998a). Implications for vocational education research of some German views on the nature of intefests. Australian Vocational Education Review, 5, 1-11.

Athanasou, J. A. (1998b). Components of intra-individual interest in vocational education subjects: Some Australian data. In L Hoffman, A. S. Krapp, K. A. Renninger, \& J. Baumert (Eds.), Interest and learning (pp. 408-419). Kiel: Institut fur die Padagogik der Naturwissenschaften an der Universitat Kiel.

Athanasou, J. A. (1998c). Perceptions of interest: A lens model analysis. Australian Psychologist, 33, 223-227.

Athanasou, J. A. (1999). Judgments of interest in vocational education subjects. Australian and New Zealand Journal of Vocational Education Research, 60-76

Athanasou, J. A., \& Petoumenos, K. (1998). Which components of instruction influence student interest? Australian Journal of Teacher Education, 23, 51-57.

Brunswik, E. (1956). Perception and the representative design of psychological experiments. Berkeley: University of California Press.

Cooksey, R. W. (1996). Judgment analysis: Theory, methods and applications. San Diego: Academic Press.

Dewey, J. (1913). Interest and effort in education. New York: Houghton Mifflin Company.

Gottfredson, L. (1996). Gottfredson's theory on circumscription and compromise. In D. Brown, L. Brooks, \& Associates (Eds.), Career choice and development (3rd ed., pp. 179232). San Francisco: Jossey-Bass.

Hidi, S. (1990). Interest and its contribution as a mental re- 


\section{Athanasou and Cooksey}

source for learning. Review of Education Research, 60, 549571.

Hursch, C. J., Hammond, K. R., \& Hursch, J. L. (1964). Some methodological considerations in multiple-cue probability studies. Psychological Review, 71, 42-60.

Renninger, K. A. (1992). Individual interest and development: Implications for theory and practice. In K. A. Renninger, S. Hidi, \& A. Krapp (Eds.), The role of interest in learning and development (pp. 361-395).Hillsdale, NJ: Erlbaum,

Schiefele, U., \& Krapp, A. (1996). Topic interest and free recall of expository text. Learning and Individual Differences, $8,141-160$

Schiefele, U., Krapp, A., \& Winteler, A. (1992). Interest as a predictor of academic achievement: A meta-analysis of research. In K. A. Renninger, S. B. Hidi, \& A. Krapp (Eds.), The role of interest in learning and development (pp. 183-212). Hillsdale, N.J.: Lawrence Erlbaum.

Snow, R. E. (1968). Brunswikian approaches to research on teaching. American Educational Research Journal, 5, 475-489.

Tucker, L. R. (1964). A suggested alternative formulation in the developments by Hursch, Hammond \& Hursch and by Hammond, Hursch \& Todd. Psychological Review, 71, 528530.

\section{Authors}

JAMES A. ATHANASOU is professor at the Faculty of Education, University of Technology, Sydney, P. O. Box 123, Broadway 2007, Australia [Email: Jim.Athanasou@uts.edu.au]. He teaches in the area of workplace issues and his research focuses on the area of educational and vocational interests.

RAY W. COOKSEY is professor in the School of Marketing and Management, University of New England, Armidale, NSW 2351, Australia [Email: rcooksey@metz.une.edu.au].
MANUSCRIPT PREPARATION: One (1) printed copy of the manuscript and one (1) electronic copy (in disk or via e-mail) should be submitted to the Editor. The electronic version must be in MS Word Version 6 or later to be accepted. Manuscripts typically range in length from 20 to $\mathbf{3 0}$ double-spaced pages including references, tables, and figures.

Text, references, and tables must be prepared according to the guidelines detailed in the Publication Manual of the American Psychological Association ( $4^{\text {th }}$ edition). The title page should include the title of the article, and the name, affiliation, mailing address, e-mail address (if applicable), and telephone number for each author. Each manuscript should be accompanied by an abstract of no more than 150 words. Please note: Beginning with Volume 27, all manuscripts should be prepared and submitted using the guidelines of the Publication Manual of the American Psychological Association, 5th edition. Receipt of all manuscripts will be acknowledged, in writing, within one week of receipt. Manuscripts are subjected to a double-blind refereed review process. Typically, three individuals, plus the Editor, review each manuscript. Copies of reviewers' comments and a letter indicating the disposition of the manuscript will be forwarded to the primary author in approximately three months following receipt. Manuscripts accepted for publication are usually published within one year of formal acceptance. To defray rising publication costs, authors who are not members of AVERA will be required to pay a $\$ 50.00$ fee if their manuscript is accepted for publication. Published authors will receive two complimentary copies of the $J V E R$

Send manuscripts to:
Dr. James R. Stone III, Edito
University of Minnesota
Work, Community, \& Family Ed.
Phone: 612-624-1795
1954 Buford Ave., Rm. 425
FAX: 612-624-4720
Email: stone003@umn.edu

St. Paul, MN 55108

READER COMMENTS: The Journal welcomes comments from readers on articles that have appeared in recent issues. Submitted comments much speak directly to content of the article of reference, not exceed four manuscript pages, and conform to $A P A$ reporting format These manuscripts may be sent out for peer review at the Editor's discretion. Author(s) of the original article will have an option of responding to published comments of their work.

SUBSCRIPTIONS: The JVER is included in annual membership dues to the American Vocational Education Research Association (AVERA). Journal subscriptions are $\$ 57$ per calendar year to non-members. Subscribers outside the United State should add an additional $\$ 10$ to cover mailing costs. Subscription orders and inquiries should be addressed to the Managing Editor.

REPRODUCTION RIGHTS: AVERA retains literary property rights on copyrighted articles. However, articles published in the JVER can be reproduced for academic and notfor-profit activities with the stipulation that credit is given to the JVER. All other forms of use require written permission from the publisher. This publication is available in microform. Call toll-free 800.521 .3044 or mail inquiry to University Microfilms International, 300 North Zeeb Road, Ann Arbor, MI 48106. 